\title{
The provision of educationally focused parenting programmes in England
}

Susan Hallam, Lynne Rogers, Jacquelene Shaw, Jasmine Rhamie, Institute of Education, University of London,

Correspondence, Professor Susan Hallam, Institute of Education, 20 Bedford Way, London, WC1H OAL $\underline{\text { s.hallam@ioe.ac.uk }}$ 


\section{The provision of educationally focused parenting programmes in England}

\section{Summary}

In recent years there has been an increased recognition of the importance of parenting and the way in which parenting programmes can be an effective intervention in changing behaviour and parent/child interactions. The aim of this research, funded by the DfES, was to provide a map of parenting programme provision in England. In the first phase of the research data were collected through responsible Local Authority (LA) officers from all LAs in England to explore the different types of parenting programmes available. On the basis of findings from phase 1 of the research, twenty examples of particular types of parenting programmes were selected for more in depth study. In phase two field-visits were undertaken to parenting programmes and interviews undertaken with staff. The paper reports the extent to which LAs have access to or provide educationally related parenting programmes in England and the nature of that provision including infrastructure, organisation and funding; the set up of programmes and referral systems; participants and dropouts; types of programmes; programme content and follow up; evaluation; staff training; and difficulties experienced in providing such programmes and for parents in accessing them. The findings are discussed in the light of the implementation of Parenting Orders and the operationalisation of the Anti-social Behaviour Act 2003 . 
The provision of educationally focused parenting programmes in England

Keywords: parenting, behaviour, adult learning 


\section{The provision of educationally focused parenting programmes in England}

\section{Introduction}

The Anti-social Behaviour Act 2003 introduced new powers for Local Authorities (LAs) to apply for a parenting order to help address children's behaviour in school. A parenting order compels a parent to attend a parenting programme and to fulfill other requirements as determined necessary by the court for improving their child's behaviour, e.g. ensuring that the child arrives for school on time. Parenting orders have been available for some time following prosecution for non-attendance. Under the Anti-social Behaviour Act they are now available following a permanent exclusion or a second fixed term exclusion within 12 months. They are used when a pupil has been excluded for serious misbehaviour and where parenting is considered a factor in the child's behaviour and the parents are unwilling to engage with the LA or school in attempting to bring about change on a voluntary basis.

In the past, some LAs encouraged parents who had not been issued with a Parenting Order but whose children were experiencing school attendance problems, to attend such programmes on a voluntary basis. The Anti-social Behaviour Act (2003) enabled schools and LAs to arrange parenting contracts which are voluntary and will involve the parent agreeing to carry out specific actions to improve their child's attendance or behaviour in return for the LA or school providing or arranging support, typically a parenting programme, with which the parent will be required to co-operate. In all of these instances, the aim of parenting programmes is to encourage parents to satisfy their responsibilities by equipping them with skills to enable them to deal with their child's behaviour or attendance problems. The aim of this research was to 
examine the provision of parenting programmes in LAs in England with particular reference to the need for them to have access to sufficient programmes to address issues relating to improving attendance and behaviour in school in the light of the Anti-social Behaviour Act 2003.

In recent years there has been an increased recognition of the importance of parenting and the way in which parenting programmes can be an effective preventative service (Hoghughi, 1998; Desforges and Abouchaar, 2003). In a review of the literature Desforges and Abouchaar (2003) concluded that parental involvement in the form of 'at home good parenting' has a significant positive effect on children's achievement and adjustment even after all other factors shaping attainment have been taken out of the equation. In the primary age range the impact caused by different levels of parental involvement is much greater than the differences associated with variations in the quality of schools. This is evident across all social programmes and ethnic groups. Parent programmes could therefore be an important element in supporting improvement in attendance, behaviour and attainment at school.

Most parenting programmes are based on one of two main approaches, behavioural or improving relationships. The former seem to be more effective in changing children's behaviour while the latter seem to have more positive effects on the cohesive functioning of families (Barlow, 1997). Practices in delivering parenting programmes in the UK in relation to the former are largely derived from the work in the USA of Webster-Stratton with conduct disordered young children and their families, the latter from Bavolek's approach with dysfunctional families (Lloyd, 1999). Much of the research to date has concentrated on developing the parenting skills of those with young children. There has been much less 
systematic study of parenting programmes for the parents of adolescents and even less on the extent to which parenting programmes can improve educational outcomes. In the UK, the most encompassing evaluation of parenting programmes relating to adolescents has been in relation to juvenile offending (Ghate and Ramella, 2002). Ghate and Ramella (2002) identified several approaches adopted in the programmes which could be classified as broadly 'preventative' or 'therapeutic', although some combined both approaches. The work with parents generally addressed issues related to dealing with conflict and challenging behaviour; learning to constructively supervise and monitor young people's activities; setting and maintaining boundaries; communication and negotiation skills; and family conflict in general. Parents were positive in their evaluations of the programmes and there was also evidence of positive change in the young people, including improved communication and mutual understanding, a reduction in conflict with parents, and improved relationships. Reconviction rates reduced by nearly one third, offending dropped to $56 \%$, and the average number of offences was reduced by half. An important additional positive outcome was the benefit to parental relationships with younger children. To date no research has examined the availability, or nature of parenting programmes designed to impact on educational outcomes. The purpose of this research is to examine the provision of parenting programmes within LAs for addressing issues relating to attendance and behaviour in school in light of the Anti-social Behaviour Act 2003.

\section{Methodology}

The research was undertaken in two phases. In Phase 1 telephone interviews or e-mail conversations were conducted with responsible LA officers in England to establish their use of parenting programmes, the providers that they used and how programmes were funded. The 
providers of these programmes were also contacted and interviewed. The purpose of the interviews was to obtain detailed information about the nature of any parenting programmes operating in the LA either voluntary or compulsory, the nature of the relationship between the LA and the parenting programme provider, how parents were referred to the programmes, the extent of take up of the programmes, the type of parents accessing the programmes and why they participated, and which parents dropped out and why. Detailed information was also obtained about the approaches and teaching methods used in the programmes; differences in curriculum and organisation of programmes catering for parents of pupils with different types of problems, particularly behaviour and attendance; the time scales involved in delivering different types of parenting programmes; how the programmes were quality assured and evaluated; and the availability of data for monitoring the progress in school of the children of the parents attending the programmes. Any difficulties experienced in providing the programmes were also identified. One hundred and thirty four of the 150 LAs in England (89\%) made a response of some kind to the telephone/e-mail interview. On the basis of information that they provided, questionnaires were sent out to 296 parenting programme providers. Responses were received from 158 (53\%). Of these 30 indicated that they no longer ran programmes.

On the basis of Phase 1 of the research, 23 examples of contrasting approaches to parenting programmes were selected for more in depth study. The selection of these examples was made by the steering committee at the DfES and the research team and was informed by the views of a quality assurance and advisory group set up at the Institute of Education. The selection took account of different types of programmes for parents of children with different types of problems, geographical area (rural, urban), level of deprivation in the LA, and involvement in 
other DfES programmes, e.g. Behaviour Improvement Programme, Excellence in Cities. For each of the 23 programmes visited more detailed information was obtained regarding the structure and content of parenting programmes, how they were funded, how quality was assured and how their effectiveness was evaluated. The interviews with those responsible for and involved in running parenting programmes explored in greater depth the issues raised in the survey. Thirty-three interviews were undertaken with providers and facilitators.

The qualitative data from the survey were coded to enable frequencies to be computed. SPSS was used to analyse the quantitative data relating to the survey of LAs. A consultative conference was held with representatives of participating LAs, providers of parenting programmes, the DfES and OfSTED to facilitate the validation, clarification and interpretation of findings.

\section{Findings}

\section{Infrastructure, organisation and funding}

Overall, 134 (89\%) LAs responded to requests for information, either by completing the questionnaire (92), undertaking a brief telephone interview (22), passing the questionnaire onto a programme provider (11) or providing a list of programmes (9). In many cases, although LAs responded, they supplied little or no information about parenting programmes because they had few relevant structures or personnel in place. Sixty-one percent of LAs provided detailed information regarding the programmes available in their LA. Table 1 provides a breakdown of responses from each region of the country and the number of programmes from which data were collected in each region. Questionnaires were also completed by 128 
parenting programme providers $53 \%$ of those asked for information. These were contacted through the LAs and are therefore representative of the types of programmes to which LAs refer parents whose children have difficulties relating to behaviour or attendance at school.

\section{Table 1 about here}

\section{Local Authorities and parenting programmes}

Of those LAs responding, there was wide variability in the number of programmes reported. Thirty two LAs (21\%) listed one provider, $25(17 \%)$ listed 2, $12(8 \%)$ listed 3, $8(5 \%)$ listed 5, $4(3 \%)$ listed 4, $3(2 \%)$ listed 6, while 7 and 8 were listed by only one LA each. Overall, 64 LAs (43\%) provided no information about available programmes.

The providers of parenting programmes were asked to state under the auspices of which organisations their programmes operated. There was wide variation. The largest providers in the participating sample were Barnados (13\%) and Youth Offending Teams (13\%).

There was variability between LAs in the personnel with responsibility for parenting programmes. The three most commonly reported responsible personnel were a senior level Education Officer (45\% of responding sample), an Education Welfare Officer or Social Worker $(23 \%)$ or a Service Manager (12\%). The latter was often related to social inclusion. Five LAs (5\%) had personnel for whom parents or families were a key focus. Other personnel mentioned by less than $2 \%$ of LAs included the Head of Behaviour Support Services, Head of School Plus, and the Youth Offending Team. Several LAs reported that they were rethinking their structures to enable them to appoint personnel with dedicated responsibilities for 
parenting programmes.

\section{Co-ordination of parenting programmes}

Overall, most LAs had few, if any structures in place, in relation to the co-ordination of parenting programmes. There were a few exceptions to this, for instance, LAs providing a coordinator who acted to provide information about programmes available locally usually run under the auspices of the voluntary sector. In some cases the LA was developing a range of programmes to satisfy educational needs. There was consensus that parenting programmes should be given a higher profile and that they should be made available for all parents. Schools were seen as one avenue for disseminating information about programmes.

\section{Funding}

Forty six LAs responded to a question about funding (31\%). Figure 1 illustrates the proportions of funding derived from different sources. Eleven percent of all LAs indicated that their funding came from the LA, $9 \%$ did not specify the sources of their funding, $8 \%$ indicated that they had no funding, $7 \%$ indicated that funding came from Youth Offending Teams, $6 \%$ from the Children's Fund, 5\% from Social Services. Two percent received funding from the Behaviour Improvement Programme. Other sources for a very small number of LAs included the Family Learning Budget, Sure Start, Relate, the Parent Partnership Fund and the Adult Education Budget. 


\section{Figure 1 about here}

Providers were also asked how their programmes were funded. Table 2 sets out the key funders. Concerns were expressed about the transitory nature of funding from the various sources, its lack of stability, the need to constantly seek out new sources, and its inadequacy to satisfy need. To overcome funding difficulties some programmes were exploring the use of peer-support, Family Centres, and involving more organisations where employees ran parenting programmes as part of their normal work. In a few cases providers made a small charge for attendance at programmes unless parents were on income support. However, this was perceived as having an adverse effect on the recruitment of needy parents. A further difficulty was providing funding to support parent's attendance, for example for transport and crèche facilities.

\section{Table 2 about here}

\section{Impact of the Anti-social Behaviour Act}

LAs expected that the Anti-social Behaviour Act would increase the need for places on parenting programmes and indicated that current provision would then be insufficient. Forty LAs indicated that they were currently experiencing difficulties in relation to the provision of parenting programmes $(27 \%)$, although $45 \%$ of providers indicated that they were meeting demand. Eight LAs reported that they had waiting lists for existing programmes. 


\section{The set up of programmes and referral procedures}

\section{Provision for parents attending compulsorily or voluntarily}

Only 36 LAs responded to a question asking if separate provision was available for parents attending compulsorily or voluntarily. Thirteen (9\% of all LAs) reported that they had specific programmes for those attending voluntarily rather than compulsorily. Only $3 \%$ of providers (6) ran separate classes for voluntary and compulsory referrals. Generally, programmes did not differentiate provision on the basis of the nature of the referral, in part because, overall, few parents had been ordered to attend. Referrals were generally made before parents were taken to court. Parents referred compulsorily were reported to have more negative attitudes initially than those referred voluntarily but providers indicated that the two groups could be integrated providing that the compulsorily referred parents had the opportunity to express their anger and frustration in individual meetings prior to the start of the group programme. The skill of the facilitator was important in maintaining their engagement during the programme. Those on compulsory orders chose whether to share the status of their referral with other group members. Programmes exclusively for parents on compulsory orders were related to crime and not education. In some cases parents referred on a compulsory order were seen on a one-to-one basis.

Typically, when parenting programmes were hosted by schools attendance was voluntary and all parents were invited and welcomed into the programme. In some schools parallel courses were run for children. As programmes developed within the school traditions developed, and 
parents often asked to attend, although those which the school would have liked to attend did not always do so. Overall, persuading parents to attend programmes was viewed as problematic. Forty three LAs responded to a question asking if they experienced difficulties in engaging parents. Of these 9 said that they did, 6 indicated that they found difficulties in meeting parents' needs, 3 indicated that attracting families at risk was a problem, while 1 LA stated that they had difficulties in establishing groups.

\section{Programmes for parents of children of different ages}

Thirty six LAs responded to a question asking if they had provision for parents of children of different ages. Seven percent of LAs (11) indicated that they provided programmes for the parents of children of 5 years and under, 22\% (33) reported that they provided programmes for

the parents of pupils aged 5-12 and 11-17 years. Sixty-nine percent of providers responded to a similar question (89). Fifty four (42\% of all providers) indicated that they ran programmes for parents of the under fives, 51 (40\% of all providers) ran programmes for parents of children aged 5-11 and 54 (42\%) indicated that they provided programmes for parents of children aged 12-17. Overall, there seemed to be insufficient provision at LA level to satisfy the needs of parents with children of different ages.

\section{Programmes for different types of parents}

Providers of parenting programmes were asked if they ran programmes for different types of parent. Twenty-nine providers indicated that they ran single gender programmes (23\%), 46 held programmes for parents of different ages (36\%), while 52 indicated that they provided 
programmes for children and parents with different needs (41\%). Some providers had programmes for groups of parents with different levels of problems:

\section{Longevity of programmes}

There was considerable variation in the longevity of programmes reported by LAs. One programme was reported as having been running for nine years while one had only been running for 6 months. Most had been running for 1 (7 LAs), 2 (6 LAs), or 3 years (7 LAs). Similar variability was reported by providers with a range from 4 months to 20 years.

\section{Location of programme delivery}

One hundred and twenty-five providers responded to a question asking where parenting programmes were held. Typically, programmes were held in community settings $(89,71 \%)$. Twelve were provided in schools (10\%) and 24 in both types of location (19\%). Where parenting programmes were operating in schools, this was usually at primary level. Programme facilitators reported that host schools were supportive and that appropriate facilities were available, although lack of space was sometimes an issue. School based programmes were reported to have very low drop out rates, perhaps because there were no transport difficulties for attending parents. They were reported to help in improving home-school relations, increasing co-operation, facilitating consistent approaches to dealing with children's behaviour between home and school, and made the monitoring of the impact of the programme more effective. 


\section{Frequency and timing of sessions}

Thirty-one LAs (21\%) and 73 programme providers responded to questions about the frequency of programmes. Twenty-nine LAs indicated that programmes were held weekly, while 2 indicated that they were held fortnightly. The 73 providers who responded to this question $(57 \%)$ indicated that their programmes ran weekly. Twenty-nine LAs provided information about the time of year in which the programmes started. Thirteen reported running programmes termly, 1 indicated that programmes ran all year, 5 said several times a year, 4 had a rolling programme, and 6 said that the programmes were tailored to meet the needs of the parents. One hundred and twenty-nine providers provided information about when their programmes ran. Fifty ( $81 \%$ of those responding) indicated that the programmes ran termly.

Of the 125 providers providing information about the time of day when programmes operated, $23 \%$ only provided programmes in the morning, $7 \%$ only in the afternoon, $6 \%$ only in the evening and $2 \%$ at lunchtime. Nine percent reported organizing programme schedules according to the needs of parents.

\section{Number and length of sessions}

Thirty eight LAs and 119 providers indicated the number of sessions that they ran. Responses ranged from 1 to 14 sessions. The most common responses from providers were 8 sessions $(25$ responses), 10 sessions (25 responses) 6 sessions (19 responses) and 12 sessions (9 responses). The most frequent response from LAs was 8 sessions (12 LAs). The programmes visited tended to vary in length between 6 to 15 weeks with courses running for between 1 to 3 hours. 
Providers believed that the programmes needed to be contained within one academic term, although a number of parents and facilitators indicated that the programmes were too short. The number of sessions run was not the only issue, the length of each session was also important. Twelve LAs and 78 programme providers gave information about the length of sessions. Most lasted from 1 hour to 3 hours 15 minutes, typically 2 hours (10 LAs, 58 providers). Parents and providers both indicated a need for follow up sessions.

\section{Referrals to programmes}

Fifty eight LAs responded to a question about self-referral. Of those, 27 LAs (47\% of responding LAs) indicated that parents could self-refer, as did 91 providers (71\%). LAs and providers were asked how parents were referred to programmes. Ten LAs (7\% of all LAs) said that referrals could be made through the Youth Offending Team, 40 indicated that referrals were made through the LA $(27 \%)$, while $15(10 \%)$ reported that referrals were made through the courts. Fourteen LAs $(9 \%)$ reported that referrals were made through schools, while 8 LAs $(5 \%)$ reported that referrals were made through social services. Only 1 LA reported that referrals were made through the PRU (1\%). Three reported that referrals were made through the school nurse (2\%). One LA reported that referrals were made through Child and Family Court Advisory Support Service (CAFCAs) (1\%), 3 through CAMHS (2\%), 5 through Health Visitor Services (3\%), and 10 from other unspecified sources (7\%). One hundred and twentyfive providers responded in relation to how parents were referred to the programmes. The details of the responses are set out in Table 3. Most referrals were made through a range of health or social services related agencies. One hundred and ten providers responded to a question asking specifically whether LAs referred parents whose children had attendance or 
behavioural problems. Of those 63 indicated that they did (57\%). This constituted $33 \%$ of the participating sample.

\section{Criteria for referrals}

LAs and providers were asked if they had criteria for referring parents to programmes. Thirty LAs (13\%) responded, 23 (15\% of all LAs) indicating that they did. The field-work revealed the criteria adopted. These were related to the child and his/her behaviour, the extent to which s/he was seen as out of parental control, the extent to which behaviour was seen to be preventing the child's access to the curriculum, possible risk of exclusion from school, poor attendance at school, and the prevention of anti-social behaviour. In some cases referral was related to a compulsory order made by the courts, but this was rare. LAs preferred to refer parents on a voluntary basis before cases reached the point where legal proceedings were instituted.

\section{Table 3 about here}

In most LAs, parents needed to live or, in some cases work, within the appropriate geographical area. The sources of referral within LAs varied but might include the school, the Behaviour Support Team, the Education Welfare Service, as a result of child protection issues, or on the basis of the child's vulnerability. Generally, LAs reported consideration of each individual case. Referrals to particular programmes depended on the age of the child. LAs also took account, in many cases, of the parents' request to receive help and support, their need for help specifically with parenting skills, their willingness to attend, their commitment to 
complete the course, and the extent to which attendance at the programme was due to poor family relationships and lack of communication.

Where parents were ordered to attend each individual case tended to be assessed in terms of whether group work or one-to-one tutoring would be most appropriate. Sometimes programmes were not available in the appropriate geographical location or there was a waiting list. If no programme was available locally then one-to-one support might be offered. Usually, LAs preferred group work as it was perceived as more effective educationally and financially.

One hundred and eighteen programme providers responded indicating whether they had specific criteria for referral. Sixty-six $(35 \%)$ indicated that they did. Overall, these were similar to those of LAs, although some programmes excluded particular groups of parents where the family difficulties extended beyond parenting, for instance, mental illness, drug or alcohol abuse, sexual abuse or complete family breakdown, although there were exceptions to this. In some cases parenting programme providers expected work to have already been undertaken by primary care/tier one services, others insisted that the referring agency must be committed to providing ongoing field support. In contrast, some were prepared to take any parent who expressed interest and groups might include a mixture of parents, single partners, even grandparents. Such programmes were open to the whole community and had much broader aims. Where programmes were school based, parents appreciated an open invitation to attend as this removed any sense of stigmatization or failure.

\section{Participants and dropouts}




\section{Number of parents participating in parenting programmes}

Only 34 LAs were able to provide figures for the number of parents referred to parenting programmes. The number varied from none to 448 with a mean of 42 . This variation depended in part on the size of the LA but also on local policies regarding referrals. When parenting programme providers were asked how many parents were on each programme 124 responded. There was wide variation from 4 to 35 . The most common responses were 10 parents (29\%), 12 parents $(27 \%), 8$ parents $(13 \%)$ and 15 parents $(9 \%)$.

\section{Compulsory parenting orders}

Fifty-four LAs (36\%) responded to questions regarding the number of parents who had received compulsory orders in the last academic year. Of these the majority (19 LAs, $13 \%$ of all LAs) reported that no parents had been issued with compulsory orders. Seven (5\%) reported that two compulsory orders had been issued, $6(4 \%)$ that 6 compulsory orders had been made, $5(3 \%)$ that one had been issued, $4(3 \%)$ that 4 had been issued, and $3(2 \%)$ that 3 had been issued. Two (1\%) reported that 5 and 9 had been issued while individual LAs (.5\% each) reported that 7, 8, 12, 4, 17 and 18 compulsory orders had been made. The number of parents attending programmes following receipt of compulsory orders was also reported by LAs to be low. Five (3\% of all LAs) reported that 2 parents had attended, 4 LAs reported that 1 and 6 had attended (3\% each), 3 LAs ( $2 \%$ each) reported that 0 and 4 parents had attended. Two LAs $(1 \%)$ reported that 5 parents had attended and single LAs (.5\% each) reported that 3, 8,9, 10 and 12 parents had attended. 
Programme providers were also asked how many parents in receipt of compulsory orders had attended programmes. Seventy-seven providers responded to this question. Most indicated that no parents with compulsory orders were currently attending programmes $(32,42 \%$ of responding sample). However, a small number of programmes were catering for substantial numbers of such parents. One programme had had 14 referrals but most providers who responded had none $(15,36 \%$ of the responding sample). Out of the total number of programme providers participating in the survey only $21 \%$ had received compulsory education related referrals.

\section{Voluntary referrals to parenting programmes}

When asked about voluntary referrals to parenting programmes 34 LAs responded. The number of voluntary referrals varied from 0 (8 LAs) to 350 (1 LA) with a mean of 46 . Twentythree LAs responded to a question about how many voluntary referrals related to attendance issues. The mean response was 12 . Seven LAs reported that parents were voluntarily referred to programmes for reasons other than attendance (5\%) usually behaviour.

Ninety-nine providers $(77 \%)$ indicated how many voluntary referrals they had had in 20022003. The range of responses was wide from 0 to 800. Six providers reported 50, 5 providers reported 20, four providers reported 10, 12, 30 and 100. The mean was 68. Eighty-one providers (63\%) indicated how many LA referrals had been made on a voluntary basis. Fifty (39\%) reported that they had received none. There was wide variation in responses from 0 to 60. The mean was 7 . Only 2 providers indicated that they had referrals from other agencies ( $21 \%$ of the participating sample). When asked how many of those attending voluntary actually 
attended 70 providers responded (55\%). The responses varied from 1 to 143 . The mean was 28 . Evidence from the field work indicated that there were difficulties in persuading some parents to attend.

\section{Drop outs}

Only 20 LAs responded to the question asking how many parents in receipt of compulsory orders had dropped out. Of these 50\% (10 LAs) indicated that no parents had dropped out. Six indicated that one parent had dropped out (30\%). Two LAs said that 2 parents had dropped out, one said that 3 had dropped out and 1 reported that 6 had dropped out. Thirty-four providers responded to the same question, 20 indicating that they had no drop-outs (16\% of the participating sample), while individual programmes reported higher levels of drop out with a maximum of 7 .

LAs were also asked to give an indication of the number of voluntary referrals who dropped out of programmes. Nineteen LAs responded to this question (13\%). Of these, 6 reported no dropouts. In some cases the number of drop-outs was high, although this has to be viewed within the context of the number of referrals. Sixty-four providers responded to questions about drop-outs who were voluntary referrals (59\%). Nine of those indicated that there were no dropouts $(7 \%)$. The range of drop-outs was from 1 to 33 . The mean drop out rate was 5 .

The parenting programmes visited during the fieldwork had low drop-out rates. They adopted a range of strategies to ensure good attendance including visiting parents prior to the start of the programme, following up non-attendance immediately, and providing one-to-one support 
where group work was not appropriate.

\section{Types of programmes}

\section{Approaches adopted to delivering parenting programmes}

Forty four LAs (29\%) responded to questions about the models underpinning the programmes. Eight (18\%) had their own model. Seven (16\%) adopted the Webster Stratton model, while a further 7 (27\%) stated that different curriculum approaches were adopted for different types of problems. Four (9\%) adopted a Cognitive Behaviourist approach, $4(9 \%)$ the 'Making Changes' model, 3 (7\%) Positive Parenting, 3 (7\%) the Living with Teenagers approach, 3 (7\%) the Family Caring Trust model, and 2 (5\%) the Let's Talk' approach. Single LAs (2\% each) reported adopting a Systematic Counseling approach, the Parent Plus approach, the Teaching Protective Behaviour model, the National Child Care Training Format, the Stepping Stones approach, Systematic Training for Effective Parenting, and Strengthening Families, Strengthening Communities. One to one teaching was adopted by 8 LAs (18\%) and other unnamed methods by 13 (30\%). Providers also indicated the models which underpinned their approach (see Table 4). There was variety in the type of responses given, some referred to types of programme, others to the methods adopted. Twenty-one (16\%) programmes reported that they adopted different curricula for different types of parenting problems.

\section{Table 4 about here}




\section{LA run courses}

Some LAs had developed courses (usually through the Education Welfare Service) focused on education related issues, run in schools, which sometimes had parallel elements for pupils. Such programmes were effective because of ease of access for parents, although there were sometimes difficulties relating to space in school, and some parents were reluctant to attend if their own school experiences were poor.

\section{Programme Content and follow up}

\section{Contact before the start of the programme}

There was variation in the extent to which parents were engaged with the programme before it started. Pre-programme visits allowed parents to explain their home situation, and to talk about what they wanted from the course, and enabled providers to assess their suitability for the programme. Those ordered to attend had an opportunity to discharge anger before the beginning of the programme. Prior meetings also served to reduce anxiety in some parents. Some parents merely received a pre-programme letter and initial contact was made by the facilitators during the first session. Where there were parallel programmes for parents and children, prior contact was sometimes made with the children to reduce anxiety and ensure that they understood why they were being asked to attend.

\section{Methods adopted}


Whatever named approach the parenting programmes adopted all, with the exception of one-toone work, were based on group work and the facilitation of discussion relating to parenting issues. They focused on similar topics including improving relationships in the home and developing behaviourist skills for managing children's behaviour. Practising skills and learning from the children's responses to particular strategies was crucial. The implementation of a rewards system was reported as being particularly effective. Programmes introduced the idea that rewards did not need to be expensive, but could be based on parents spending time with their children and offering praise. Much of the impact of the programmes came from the increased confidence that the parents gained as they implemented the various strategies. Crucial to the success of programmes were the interactions between parents, and the skills of the facilitators. The latter had to be able to listen and be supportive while ensuring that participants respected each other within the discussions.

\section{Ongoing support and follow up work}

Some LAs had a telephone help-line which was available for all parents including those on programmes. This provided support in between sessions if it was required. Where families were facing serious problems, some providers required that parents/carers were offered ongoing support while the programme was running.

Parenting programmes varied in the extent to which they had follow up sessions. Some provided a few sessions while others encouraged parents to set up their own ongoing support groups, although these sometimes experienced difficulties in finding venues, and providing funding for transport and crèche facilities. Where formal support groups were not convened 
facilitators often encouraged parents to swap telephone numbers and keep in touch. Parents were frequently encouraged to take other courses on completion of the initial programme.

\section{Programmes acting as brokers for other services}

In the survey, 29 (19\%) LAs responded to a question asking if parenting programme providers acted as brokers to parents for other services. Of these $72 \%$ indicated that this was the case. Eighty-six providers also indicated that they acted as brokers for other services (67\%), while also highlighting a lack of adequate support available from other agencies.

\section{Evaluation of parenting programmes}

Of the $47 \mathrm{LAs}(31 \%)$ responding to a question about programme evaluation, 30 (64\%) indicated that they had a formal evaluation mechanism in place. Twenty three LAs (15\%) provided information about the type of evaluation. Seven used questionnaires (5\%), 12 reported self-evaluation by parents and facilitators (8\%), and 4 reported parental evaluation without specifying the means (3\%). One hundred and nineteen of the participating programmes indicated that they had formal evaluation mechanisms in place (93\%). Figure 2 indicates the types of strategies adopted. The most common was self-evaluation by parents and facilitators (68 programmes, 53\%). Eighteen providers (14\%) indicated that different types of evaluation were adopted for different types of programmes. Some providers used before and after measures to assess levels of change in parents but this was relatively rare, some completed these assessments during home visits. Some parents experienced difficulties with literacy making written evaluation difficult. 


\section{Figure 2 about here}

Only twenty-eight providers (22\%) indicated that they reported the outcome of evaluations to the LA. Where programmes were not run by LAs there was limited communication about the impact of the programmes on parents and generally no follow up. In most cases providers did not monitor the effects of programmes on the children. Thirty LAs $(20 \%)$ responded to the question about the monitoring of school attendance of the children of the parents who were attending the programmes. Of these, 24 indicated that they did monitor attendance $(16 \%)$ but they did not monitor school exclusion.

The quality of programmes was not usually formally assessed, although there were some exceptions. Where programmes were run through LA services, for instance, Adult Education there was normally an appraisal system for tutors. Where courses were accredited other quality assurance mechanisms were often in place. Some national providers of programmes offered peer supervision to facilitators. What was lacking was systematic evaluation of the long-term impact of the programmes on parents, families and children, particularly in relation to educational outcomes.

\section{Staff training}

Staff were recruited from a variety of backgrounds. Those working within education where work directly involved children as well as parents tended to be Educational Psychologists, Education Welfare Officers, or Educational Social Workers. Parent group leaders came from a wide range of backgrounds including family therapists, school nurses, nursery nurses, school 
teaching assistants, health visitors, ex head teachers. Some had an education background. Some staff had been recruited following their own attendance on a parenting programme and had no previous related experience. Many programme facilitators were part time and hourly paid, and the work was seen as low status leading to a high turnover. Despite this many programmes reported no difficulties in recruiting staff. Those programmes run under the auspices of the LA were more often staffed by full time staff the parenting programme work being a relatively small part of their duties. There was recognition that to provide more programmes particularly in every school there would be a need for more facilitators. It was suggested that these could be recruited from those already working in education including home-school link workers, pastoral care teachers, school nurses, and learning support assistants.

In the survey, 109 programme providers $(85 \%)$ indicated that all of their staff were trained in the model being used in their programme. Thirty-three programmes $(26 \%)$ indicated that their staff had a training qualification. Training was undertaken in a range of ways depending on the nature of the programme. In some cases, newly recruited facilitators were parents who had themselves attended programmes in the past. Training was sometimes accredited. At the time of the research there were no nationally recognised qualifications for those providing parenting programmes. Some programmes required that facilitators were supervised. Where this was the case, there was often insufficient funding for this to be undertaken appropriately.

\section{Perceived problems in relation to the delivery of parenting programmes}

Those providing parenting programmes were given the opportunity to report any difficulties that they had experienced. The findings are reported in Table 5. The most common difficulties 
related to the provision of crèche facilities (35\%), venues (25\%), funding (25\%), transport $(17 \%)$, and recruiting parents $(15 \%)$.

\section{Table 5 about here}

\section{Discussion}

The Anti-Social Behaviour Act 2003 implicitly requires LAs to provide sufficient parenting programmes for those parents referred by the courts to attend. The findings reported here demonstrate that at the time of the research the systems in place for co-ordinating and providing parenting programmes were fragile. Most LAs did not have adequate provision themselves nor did they provide appropriate means of co-ordinating or monitoring the quality of programmes provided by charitable organizations, although there were some examples of existing good practice where there were well established networks providing information to the public about what was available and where voluntary and statutory bodies worked well together (see Hallam et al., 2006). These may act as models for future development.

There were few parenting programmes which were specifically designed to address issues relating to education. Most parenting programme provision was of a more general nature and focused on relationships and parental control of their children. Links with schools were few and evaluation of the educational impact on children infrequent. Some LAs were developing school-based provision and this was seen as successful in providing a bridge between home and school and leading to improved behaviour and attendance. Such programmes offer the most promise for successful outcomes in the future with parents referred voluntarily or 
compulsorily attending together. In the longer term, to facilitate attendance, programmes need to be available in every school and all parents encouraged to attend. This will serve to reduce stigma and develop a cultural norm of attendance. The required increase in trained facilitators may be met through the training of education staff and parents who have already completed programmes. The efficacy of the latter has been demonstrated. Where open programmes have been run in schools those attending have become advocates for programmes in their local community. This enthusiasm could be an important vehicle through which to engage the most needy and reluctant parents in the community.

Providing programmes in schools is not without its problems. There is a need for crèche facilities, transport, and appropriate accommodation. This requires funding as does training for facilitators. Funding for the programmes came from a variety of sources and was insecure in the long and short term. It was also inadequate to meet need. At the time of the research, there had been relatively few compulsory parenting orders made relating to education. If the numbers of these increase as a result of the Anti-social Behaviour Act 2003 funding will need to be made available as most LAs do not currently have sufficient capacity.

\section{References}

Barlow, J. (1997) Systematic Review of the Effectiveness of Parent-Training Programmes in Improving Behaviour Problems in Children aged 3-10 years. (Oxford, Health Services Research Unit, Department of Public Health) 
Desforges, C. \& Abouchaar, A. (2003). The impact of parental involvement, parental support and family education on pupil achievement and adjustment: a literature review. (London, DfES)

Ghate, D. \& Ramella, M. (2002) Positive Parenting: The National Evaluation of the Youth Justice Board's Parenting Programme. (London, Policy Research Bureau)

Hallam, S. Rogers, L., \& Shaw, J. (2006) Improving children's behaviour and attendance through the use of parenting programmes: An examination of practice in five case study Local Education Authorities, British Journal of Special Education, 33(3), 107-113.

Hoghughi, M. (1998) The importance of parenting in child health. British Medical Journal, $316,1545$.

Lloyd, E. (1999) (Ed) Parenting Matters: What works in parenting education? (Ilford Essex, Barnados). 
Table 1: Geographical spread of survey responses

\begin{tabular}{|c|c|c|c|c|c|c|}
\hline Region & $\begin{array}{l}\text { Questionnaire } \\
\text { completed by } \\
\text { LA }\end{array}$ & $\begin{array}{l}\text { Telephone } \\
\text { contact made } \\
\text { but } \\
\text { questionnaire } \\
\text { not completed } \\
\text { for a range of } \\
\text { reasons }\end{array}$ & $\begin{array}{l}\text { Questionnaire } \\
\text { passed on to } \\
\text { programme } \\
\text { provider }\end{array}$ & $\begin{array}{l}\text { LA simply } \\
\text { provided a } \\
\text { list of } \\
\text { available } \\
\text { parenting } \\
\text { programmes }\end{array}$ & $\begin{array}{l}\text { No } \\
\text { response }\end{array}$ & $\begin{array}{l}\text { Number of } \\
\text { parenting } \\
\text { programmes } \\
\text { from which } \\
\text { data were } \\
\text { collected }\end{array}$ \\
\hline $\begin{array}{l}\text { Northwest } \\
22 \text { LAs }\end{array}$ & 13 & 3 & 1 & 1 & 4 & 14 \\
\hline $\begin{array}{l}\text { Yorkshire } \\
\text { and } \\
\text { Humber } \\
15 \text { LAs }\end{array}$ & 9 & 2 & 3 & 1 & & 19 \\
\hline $\begin{array}{l}\text { West } \\
\text { Midlands } \\
\text { 14 LAs }\end{array}$ & 7 & 2 & 1 & 2 & 2 & 7 \\
\hline $\begin{array}{l}\text { East } \\
\text { Midlands } \\
9 \text { LAs }\end{array}$ & 7 & 1 & & & 1 & 6 \\
\hline $\begin{array}{l}\text { London } 33 \\
\text { LAs }\end{array}$ & 18 & 7 & 2 & 1 & 5 & 25 \\
\hline $\begin{array}{l}\text { South } \\
\text { West } 16 \\
\text { LAs }\end{array}$ & 10 & 1 & 1 & 3 & 1 & 23 \\
\hline $\begin{array}{l}\text { South East } \\
\text { 19 LAs }\end{array}$ & 13 & 4 & 1 & & 1 & 13 \\
\hline $\begin{array}{l}\text { North East } \\
12 \text { LAs }\end{array}$ & 8 & 1 & 1 & & 2 & 7 \\
\hline $\begin{array}{l}\text { East } 10 \\
\text { LAs }\end{array}$ & 7 & 1 & 1 & 1 & & 14 \\
\hline Total & 92 & 22 & 11 & 9 & 16 & 128 \\
\hline
\end{tabular}


Table 2: Sources of funding for parenting programmes

\begin{tabular}{|l|l|l|}
\hline Funder & Number of programmes & $\begin{array}{l}\text { Percentage of participating } \\
\text { sample }\end{array}$ \\
\hline Social Services & 27 & $21 \%$ \\
\hline The Children's Fund & 24 & $19 \%$ \\
\hline YOT & 21 & $16 \%$ \\
\hline LA funding & 20 & $16 \%$ \\
\hline Health/NHS trust & 18 & $14 \%$ \\
\hline Sure Start & 16 & $13 \%$ \\
\hline Barnados & 15 & $12 \%$ \\
\hline Youth Justice Board & 8 & $6 \%$ \\
\hline Adult Education & 6 & $5 \%$ \\
\hline Self funding & 6 & $5 \%$ \\
\hline $\begin{array}{l}\text { Behaviour Improvement } \\
\text { Programme }\end{array}$ & 4 & $3 \%$ \\
\hline Schools & 4 & $3 \%$ \\
\hline CAMHS & 4 & $3 \%$ \\
\hline Education Department Funding & 3 & $2 \%$ \\
\hline Standards Funding & 3 & $2 \%$ \\
\hline Neighbourhood Renewal Fund & 2 & $2 \%$ \\
\hline Community safety/education & 2 & $2 \%$ \\
\hline Long Life Learning & 2 & $2 \%$ \\
\hline NCH & 2 & $2 \%$ \\
\hline Wider Family Learning & 1 & $1 \%$ \\
\hline Basic Skills & 1 & $1 \%$ \\
\hline Education Action Zone & 1 & $1 \%$ \\
\hline Other & 37 & $29 \%$ \\
\hline No funding available & 5 & $4 \%$ \\
\hline
\end{tabular}




\section{Table 3: Sources of referral as reported by parenting providers}

\begin{tabular}{|l|l|l|}
\hline Source of referral & $\begin{array}{l}\text { Number of } \\
\text { responses }\end{array}$ & Percentage \\
\hline Self referral & 91 & $71 \%$ \\
\hline Social Services & 88 & $69 \%$ \\
\hline Health Visitors & 71 & $55 \%$ \\
\hline LA & 55 & $43 \%$ \\
\hline Schools & 51 & $40 \%$ \\
\hline Youth Offending Team & 31 & $24 \%$ \\
\hline General Practitioners & 21 & $16 \%$ \\
\hline Child and Adolescent Mental Health Workers & 18 & $14 \%$ \\
\hline Voluntary sector & 17 & $13 \%$ \\
\hline School Nurse & 10 & $8 \%$ \\
\hline Sure Start & 9 & $7 \%$ \\
\hline Courts & 7 & $5 \%$ \\
\hline Police & 6 & $5 \%$ \\
\hline Social and Health Care & 4 & $3 \%$ \\
\hline Educational Psychologists & 4 & $3 \%$ \\
\hline Youth Justice System & 3 & $2 \%$ \\
\hline Educational and Behavioural Difficulties Workers & 3 & $2 \%$ \\
\hline Teenage Pregnancy Unit & 2 & $2 \%$ \\
\hline Multi agency & 2 & $2 \%$ \\
\hline GRIP & 1 & $1 \%$ \\
\hline Other & 30 & $23 \%$ \\
\hline
\end{tabular}

*Respondents were able to provide more than one response. Percentages therefore total more than $100 \%$ 


\section{Table 4: Approaches adopted by parenting programmes}

\begin{tabular}{|l|l|l|}
\hline Method adopted & $\begin{array}{l}\text { Number of } \\
\text { programmes }\end{array}$ & $\begin{array}{l}\text { \% of participating } \\
\text { sample }\end{array}$ \\
\hline Own programme & 31 & $24 \%$ \\
\hline Webster Stratton & 23 & $18 \%$ \\
\hline Family Caring Trust & 19 & $15 \%$ \\
\hline One to one interactions with parents & 18 & $14 \%$ \\
\hline Workshop sessions & 11 & $9 \%$ \\
\hline Positive parenting model & 9 & $7 \%$ \\
\hline Let's talk programme & 7 & $5 \%$ \\
\hline Solution Focused Brief Therapy & 6 & $5 \%$ \\
\hline Fun and families model & 5 & $4 \%$ \\
\hline Strengthening Families Programme & 5 & $4 \%$ \\
\hline Assertive Discipline & 5 & $4 \%$ \\
\hline Parentline Plus & 5 & $4 \%$ \\
\hline Coping with kids model & 4 & $3 \%$ \\
\hline Living with teenagers & 3 & $2 \%$ \\
\hline National Children's Homes & 2 & $2 \%$ \\
\hline Teaching safety in the home & 2 & $2 \%$ \\
\hline Learning through play model & 2 & $2 \%$ \\
\hline Family learning & 2 & $2 \%$ \\
\hline Nurturing programme/groups & 2 & $2 \%$ \\
\hline Family links nurturing programme & 2 & $2 \%$ \\
\hline Rainy day's play & 2 & $2 \%$ \\
\hline Transactional analysis & 1 & $1 \%$ \\
\hline Calmer, happier, easier parenting model & 1 & $1 \%$ \\
\hline Person Centred Group work theory & 1 & $1 \%$ \\
\hline The curtail C model & 1 & $1 \%$ \\
\hline Promoting effective parenting & 1 & $1 \%$ \\
\hline Promoting positive behaviour & 1 & $1 \%$ \\
\hline Parenting education model & 1 & $1 \%$ \\
\hline Range of approaches adopted & 16 & $13 \%$ \\
\hline Other non-specified models adopted & 38 & $30 \%$ \\
\hline
\end{tabular}




\section{Table 5: Difficulties reported by providers of parenting programmes}

\begin{tabular}{|l|l|l|}
\hline Difficulties reported & Number & $\begin{array}{l}\text { Percentage of } \\
\text { participating sample }\end{array}$ \\
\hline Providing crèche facilities & 45 & $35 \%$ \\
\hline Venue or finding venue & 32 & $25 \%$ \\
\hline Funding & 30 & $23 \%$ \\
\hline Transport & 22 & $17 \%$ \\
\hline Recruiting parents & 19 & $15 \%$ \\
\hline Lack of time to run programmes & 17 & $13 \%$ \\
\hline Commitment of staff once trained & 11 & $9 \%$ \\
\hline Attendance/drop out & 11 & $9 \%$ \\
\hline Difficulties in meeting the demand & 9 & $7 \%$ \\
\hline Interpreters and translation & 4 & $3 \%$ \\
\hline Difficulties in the minimum numbers required & 4 & $3 \%$ \\
\hline Lack of support from schools & 4 & $3 \%$ \\
\hline Co-ordinating multi-agencies & 3 & $2 \%$ \\
\hline Parents creating difficulties & 2 & $2 \%$ \\
\hline Finding appropriate times to suit all parents & 2 & $2 \%$ \\
\hline Coping with the numbers of referrals & 1 & $1 \%$ \\
\hline Engaging minority ethnic groups & 1 & $1 \%$ \\
\hline Other difficulties & 21 & $16 \%$ \\
\hline
\end{tabular}


Figure 1: LA reported sources of funding

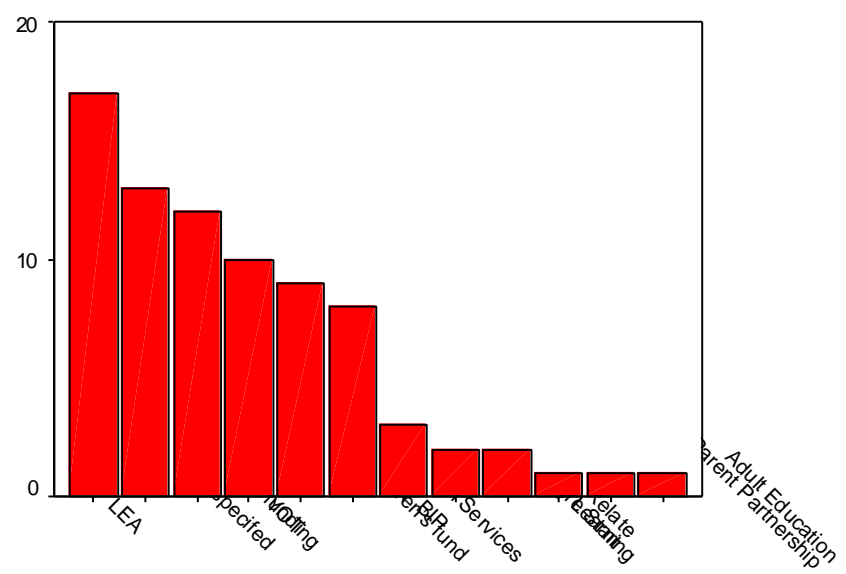

Source of funding 
Figure 2: Types of evaluation adopted by parenting programmes

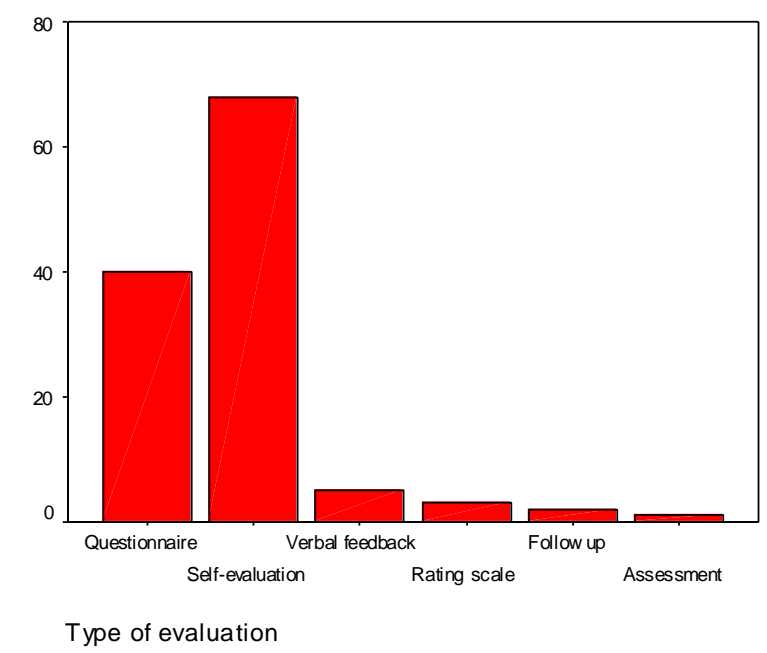

